\title{
PRÁTICAS \\ E PERCEPÇÕES \\ LINGUÍSTICAS \\ DE ALUNOS EM \\ UMA ESCOLA \\ PARAGUAIA \\ DE FRONTEIRA
}

\section{PRÁCTICAS Y PERCEPCIONES LINGÜÍSTICAS DE ALUMNOS EN UNA ESCUELA PARAGUAYA DE FRONTERA}

\author{
LINGUISTIC PERCEPTIONS AND PRACTICES OF STUDENTS IN A PARAGUAYAN BORDER \\ SCHOOL
}

Franciele Maria Martiny*

Mariana Cortez**

Universidade Federal da Integração Latino-Americana

\begin{abstract}
RESUMO: Como pressuposto ideal dos processos de mediação de leitura está o diálogo. O projeto "Vivendo Livros LatinoAmericanos na Tríplice Fronteira”, que tem como objetivos a recuperação de bibliotecas e a mediação de leitura literária em escolas de anos iniciais da fronteira (Brasil/Paraguai/Argentina), enfrenta o desafio de propor conversas literárias entre sujeitos de diferentes contextos. Nesse sentido, este artigo empírico-analítico visa à reflexão sobre as práticas e percepções linguísticas de discentes do $5^{\circ}$ Ano de uma escola em Ciudad del Este participantes do referido projeto, pois houve, de início, tensões que exigiram o reconhecimento de um cenário sociolinguisticamente complexo. Para tanto, o desenvolvimento deste trabalho consiste, primeiramente, no debate das políticas linguísticas e educacionais do Paraguai, problematizando a proposta de ensino bilíngue, para, em seguida, relacioná-las à experiência desenvolvida. O estudo, analítico e qualitativo, foca-se no diálogo estabelecido e aponta dificuldades decorrentes da presença do plurilinguismo na escola.

PALAVRAS-CHAVE: Políticas linguísticas e educacionais. Escola de fronteira. Percepções e práticas linguísticas discentes.
\end{abstract}

\footnotetext{
* Doutora em Letras pela Unioeste (Universidade Estadual do Oeste do Paraná) e Professora da área Letras/Linguística da Unila (Universidade Federalda Integração Latino-americana). E-mail:franmartiny@hotmail.com.

** Doutora em Letras pela USP (Universidade de São Paulo) e Professora da área Letras/Linguística, na Universidade Federalda IntegraçãoLatino-americana. E-mail: macortez74@hotmail.com.
} 
RESUMEN: Como presupuesto ideal de los procesos de mediación de lectura está el diálogo. El proyecto "Viviendo Libros Latinoamericanos en la Triple Frontera”, que tiene como objetivos la recuperación de bibliotecas y la mediación de lectura literaria en escuelas de los años iniciales de la frontera (Brasil/Paraguay/Argentina), enfrenta el desafío de proponer conversaciones literarias entre sujetos de contextos diversos. En este sentido, pretendemos, con el presente artículo empírico-analítico, reflexionar acerca de las prácticas y percepciones lingüísticas de estudiantes del $5^{\circ}$ grado de una escuela en Ciudad del Este, participantes de dicho proyecto, porque hubo, desde el principio, tensiones que exigieron el reconocimiento del escenario sociolingüísticamente complejo. Para tal, el desarrollo de este trabajo consiste, inicialmente, en el debate acerca de las políticas lingüísticas y educacionales de Paraguay, cuestionando la propuesta de enseñanza bilingüe, para, más adelante, hacer una relación con la experiencia desarrollada. El estudio, interpretativo y cualitativo, se concentra en el diálogo establecido e indica las dificultades debido a la presencia del plurilingüismo en la escuela.

PALABRAS CLAVE: Políticas lingüísticas y educacionales. Escuela de frontera. Percepciones y prácticas lingüísticas de los estudiantes.

ABSTRACT: The ideal premise of a reading mediation process is dialogue. The project "Experiencing Latin American Books in the Triple Frontier", while restoring libraries and developing reading mediation of literature in the first grades of schools from the triborder area (Brazil/Paraguay/Argentina), faces the challenge of proposing literary discussions among individuals from different backgrounds. In this manner, this empirical and analytical article aims to reflect upon the linguistic practices and perceptions of students from the fifth grade of a school from Ciudad del Este, associated with the aforementioned project, since, from its start, the emergence of conflicts called for a recognition of a unique sociolinguistic situation. Therefore, the development of the present article consists, firstly, on a debate of the linguistic and educational policies in Paraguay, questioning its proposal for a bilingual education, and, later, relate them to the experience that was developed on the said project. The research, interpretative and qualitative, focuses on an established interlocution methodology and reveals the stalemates associated with the multilingual scenario of that school.

KEYWORDS: Linguistic and educational policies. Border school. Students' linguistic practices and perceptions.

\section{PALAVRAS INICIAIS}

Este artigo analisa uma mediação ocorrida durante o desenvolvimento do projeto de pesquisa, ensino e extensão "Vivendo Livros Latino-Americanos na Tríplice Fronteira" ${ }^{1}$, que teve início em 2014, sendo que seus objetivos são recuperar os espaços de leitura e desenvolver práticas de mediação de leitura literária em escolas da região de fronteira: Ciudad del Este (Paraguai), Foz do Iguaçu (Brasil) e Puerto Iguazú (Argentina).

Neste estudo empírico-analítico, apenas uma das escolas será observada, a de Ciudad del Este, pois, durante as diversas atividades realizadas no ano de 2019, depois de uma situação de tensão, houve, por parte da equipe ${ }^{2}$ a necessidade de compreender esse cenário sociolinguisticamente complexo (CAVALCANTI, 1999). Isso porque, as interações orais nem sempre aconteceram de forma "harmoniosa" ao longo do processo, devido a, como hipótese, conversas literárias serem mediadas por sujeitos advindos de diversos contextos linguísticos: duas pessoas que possuem o português como língua materna e o espanhol aprendido como língua adicional (brasileiras), e uma pessoa com espanhol e guarani como línguas maternas e português como língua adicional (paraguaia). O conflito ocorreu quando os discentes questionaram por que a mediação não podia ocorrer na língua "deles”, no caso o guarani/jopará3.

Diante disso, o recorte deste artigo recai sobre a transcrição de uma prática de mediação de leitura literária desenvolvida com 16 estudantes sendo 7 meninas e 9 meninos, de 10 a 13 anos, do $5^{\circ}$ Ano do Ensino Fundamental paraguaio, que teve como objetivo reconhecer as práticas e as percepções linguísticas desse grupo. A interlocução foi filmada e, posteriormente, transcrita e

\footnotetext{
${ }^{1}$ Projeto de pesquisa realizado com financiamento CNPQ/UNIVERSAL nº. Processo CNPQ no.425119/2016-5e Edital PRPPG nº 137 , de 8 de novembro de 2018.

${ }^{2}$ Em 2019, a equipe do projeto era formada por cinco integrantes, a coordenadora e a subcoordenadora (docentes de uma instituição pública de ensino universitário), um professor colaborador e duas discentes bolsistas do curso de Letras, uma de extensão e uma de pesquisa.

${ }^{3}$ Yopará, em espanhol, ou Jopará, em guarani, é uma variedade linguística, surgida com base no espanhol e no guarani, falada no Paraguai e Norte da Argentina.
} 
interpretada de acordo com o relato etnográfico produzido.

Para situar as reflexões, é necessária a análise qualitativa e analítica (LÜDKE; ANDRÉ, 1986; BORTONI-RICARDO, 2008) dentro do escopo dos estudos sociolinguísticos e das políticas linguísticas e educacionais (HAMEL, 1988; CAVALCANTI, 1999; MORENO FERNÁNEZ, 1998; CALVET, 2002, 2007; MAHER, 2013; SPOLSKY, 2005, 2016; RAJAGOPALAN, 2011, 2013) do Paraguai (MELIÁ 1997, 2012; PERES, 2001), para, posteriormente, apresentar discussões em torno dos dados coletados durante o processo.

\section{APONTAMENTOS NECESSÁRIOS}

O termo política linguística aparece, primeiramente, conforme Calvet (2002), na Universidade da Califórnia na década de 1960, com a contribuição de vários estudiosos da Sociolinguística, entre eles Hymes, Haugen, Gumperz, Labov e Bright, a partir de discussões envolvendo as línguas e as sociedades. No entanto, o referido termo pode compreender vários sentidos e não há um consenso sobre sua definição.

Para Calvet (2002), é o Estado que possui o poder e os meios para que uma política sobre o uso de uma determinada língua seja implementada. Como exemplo, o autor cita a política decorrente da instauração dos Estados-Nações, com a legitimação de alguns símbolos, e a oficialização da(s) língua(s) nacionais. Nesse sentido, quase sempre há a escolha de uma única língua como representante da cultura nacional, apagando a diversidade inerente aos territórios, particularmente na América Latina.

Para Rajagopalan (2013), as políticas linguísticas surgem, em grande medida, dos desafios do plurilinguismo ${ }^{4}$ e são idealizadas por instituições de poder que, por vezes, têm planejamentos condizentes com as características e valores dos grupos e, por outras, surgem de forma desorientada e baseada apenas em "percepções". Por essas serem decisões que ditam as formas de ser e estar em comunidade, decretos inconsistentes, precipitados e autoritários podem afetar a própria existência diversa. Esse impasse se intensifica no contexto escolar, já que ele é concebido como espaço coletivo no qual ecoam muitas vozes que reivindicam o seu lugar, seja nas camadas discursivas superficiais, nos planos de aula ou nos meandros das conversas do recreio.

De acordo com Maher (2013), as políticas linguísticas são as intervenções nas línguas, tanto por parte dos falantes como por parte do Estado, levando em conta como essas línguas são constituídas, percebidas e utilizadas. Entende-se, assim, que as políticas linguísticas constituem as línguas, contemplando valores e funções a partir dos usos linguísticos que fazem os falantes.

Nesse sentido, de acordo com os trabalhos de Spolsky (2005, 2016), Rajagopalan $(2011,2013)$ e Sousa e Roca (2015), é preciso uma compreensão mais ampla do que seria política linguística, uma visão multidimensional do conceito, não mais restrito a ações desencadeadas por governos e organismos institucionais autorizados, mas que envolvem outros domínios, com a ação de outros agentes. Fortemente implicado nessa discussão está o espaço escolar, onde há outros atores significativos, como os diretores, coordenadores, docentes, estudantes, pais de alunos, que podem ser responsáveis pelo planejamento e gestão das políticas educacionais e linguísticas, seja com atitudes impositivas ou democráticas.

Para tanto, segundo Spolsky (2016, p. 39), "A educação escolar é por sua própria natureza um domínio comprometido com a gestão da linguagem" e, dessa maneira, as políticas linguísticas estão intimamente relacionadas às políticas educacionais, sendo elaboradas por diferentes domínios, os quais também exercem poderes assimétricos e que estão em constante disputa (RAJAGOLOPALAN, 2011).

Sousa e Roca (2015) retomam os estudos de Schiffman (2006), evidenciando uma separação entre a política linguística explícita, como aquela de direito, formalizada, declarada, e a política implícita, aquela revelada, informal, latente. Analisar apenas o que são as políticas linguísticas explícitas, institucionalizadas, restringe a investigação, sendo necessário ir além, identificando, por exemplo,

${ }^{4}$ Pelo viés do pluriculturalismo e do plurilinguismo, concorda-se com Hamel (2001) para quem o uso de tais termos apontam para uma noção de enriquecimento cultural, apesar das diferenças existentes entre línguas e culturas, principalmente quando se trata do encontro entre sociedades dominantes com sociedades minoritárias. 
as crenças e as atitudes de uma determinada comunidade sobre as línguas.

Desse modo, propõe-se, neste estudo, que, além de verificar os documentos oficiais, políticas explícitas, observe-se o funcionamento efetivo das práticas nas interações entre estudantes (às vezes docentes) na escola e no comportamento linguístico desses participantes, políticas implícitas. Sabe-se que, embora haja uma política linguística nacional, isso não significa que inexiste uma prática de uso distinta daquela, a oficial. Nesse sentido, é preciso confrontar as políticas linguísticas explícitas com as implícitas, estabelecendo uma relação entre as práticas e representações linguísticas e a conjuntura histórica, social, cultural, educacional da comunidade.

Em conformidade com esse posicionamento, Spolsky (2016) explica que as políticas linguísticas, por serem sociais, possuem três componentes significativos e, ao mesmo tempo, interligados e independentes: práticas, crenças e gestão. As primeiras, explica o autor, são consideradas as escolhas e os comportamentos observáveis, como os aspectos linguísticos escolhidos e a variedade de linguagem usada. As crenças são os valores atribuídos às variedades e aos traços linguísticos, o que nem sempre pressupõe a prática. Por sua vez, a gestão linguística é o esforço observável e explícito desencadeado por alguém ou algum grupo que tem sobre os participantes um domínio para modificar suas práticas ou crenças. Como exemplo dessa última instância, pode ser citada uma determinada lei, a qual envolve aspectos do uso oficial de uma língua ou mais línguas. Outro exemplo é o domínio familiar, Spolsky (2016) exemplifica a gestão linguística nesta instância como os esforços de pais imigrantes para manter sua língua de herança. Assim, mesmo que em casa a criança seja incentivada a aprender e a usar a língua aprendida no lar, outros domínios, como a escola, podem desencadear forte influência na ecologia linguística da casa. Nesse sentido, um novo conflito é estabelecido e pode influenciar na transmissão da língua naquele espaço.

No que tange à definição de atitudes aqui utilizada, esta é compreendida como os gestos de política linguística, sinalizando uma disposição para responder favoravelmente ou desfavoravelmente a determinada língua no universo de línguas existentes em determinado espaço plurilíngue, ou a determinado grupo linguístico. São influenciadas por fatores contextuais e por constructos históricos e, embora sejam individuais, elas têm origem em um comportamento coletivo, são construídas ao longo do processo de socialização e (re)produzidas no cotidiano, influenciando, por diversas vezes, o comportamento linguístico (MORENO FERNÁNEZ, 1998; CALVET, 2002). Sendo assim, as atitudes são evidências que demonstram as tendências individuais e grupais, envolvendo, desse modo, o uso, a aprendizagem e o ensino de línguas. Trata-se de um conceito que abrange avaliações, percepções e opiniões, aproximando-se de questões em torno do (des)prestígio linguístico. Em concordância com Botassini (2015), a crença é algo "maior", que contempla a atitude, ou melhor, ela contém os três componentes que normalmente são atribuídos à atitude: $\mathrm{o}$ conhecimento, o sentimento e o comportamento.

Com relação às políticas oficiais do Estado, na Constituição do Paraguai, promulgada em 1992, há disposto, no capítulo VII, intitulado De La Educación y De La Cultura, que o direito à educação é garantido à toda pessoa, como um processo de formação cultural a ser desenvolvido ao longo da sua vida. De semelhante maneira, a Lei geral da Educação do Paraguai n. 1.264/1998 reitera os princípios assegurados na Constituição do país.

Ademais, consta que o processo inicial de implantação da educação bilíngue no Paraguai se deu a partir de 1983, quando o MEC/Paraguai implantou o ensino bilíngue nas escolas rurais. De acordo com as considerações de Corvalán (1985), a intenção daquele programa era de dar um permiso oficial aos docentes para que pudessem utilizar a língua guarani em sala de aula, situação que era proibida anteriormente.

É de 2014 a última versão publicada pelo Ministério de Educação paraguaio do documento Programa de Estudios, o qual possui orientações e determina os conhecimentos a serem alcançadas nos referidos níveis e ciclos de ensino. O documento aborda 70\% dos currículos dos departamentos (correspondentes a estados), sendo que 30\% restante podem ser reservados para os saberes regionais e locais.

De acordo com o Manual de Aplicação (Ministério de Educação), em razão do país ser oficialmente bilíngue, incluem-se ambas as línguas no sistema educacional. Para tanto, a recomendação é que seja aplicado um Test Competencia Linguistica (2009) para as crianças do pré-escolar e/ou do primeiro grau, nas línguas guarani e castelhano. A abordagem, segundo o documento, é quantitativa 
e qualitativa, com o intuito de verificar a situação sociolinguística dos ingressantes no sistema educativo a partir da sondagem sobre seus conhecimentos e domínios sobre as línguas. Esse manual menciona os desafios impostos pela educação bilíngue do país, sendo que um dos propósitos do teste é verificar se há algum grau de bilinguismo na criança. Os dados servem (ou deveriam servir) de base para saber qual língua deve ser usada no início da escolarização do futuro discente, de modo a favorecer a aprendizagem.

O teste reflete a política desenhada na Constituição Nacional, no art. 140, que determina que a criança paraguaia deve ser educada em sua língua materna, o mesmo aparece na Ley General de educação nº 1.264 (1998). No Manual, explica-se que a língua materna é entendida como aquela que foi adquirida previamente ao processo de escolarização, na família da criança em seu contexto social, pois o objetivo seria o de desenvolver a competência nas duas línguas oficiais em uma educação bilíngue.

Apesar da menção feita nos documentos educativos sobre a educação bilíngue nas escolas paraguaias, muitas vezes, na prática, há a eleição de um único modelo que coloca o guarani como segunda língua. Assim, segundo Penner (2012), essa ideia de educação bilíngue não funciona como deveria, uma vez que os alunos convivem com práticas linguísticas e culturais diferentes das implantadas pelo Estado. Ademais, ocorre que, segundo considerações de Penner (2012), os professores também não têm formação específica nas duas línguas. Isso, sem contar que esse ser bilíngue, contemplado nas políticas oficiais, exclui outras línguas e culturas locais e, por conseguinte, seus falantes. Silenciando, por exemplo, as línguas de imigração, as demais línguas indígenas presentes no país, o português brasileiro (presente na região de fronteira), os outros falares (com as hibridizações que acontecem devido ao contato linguístico), como seria o portunhol ou mesmo o jopará. Esta última com significativa presença no cenário descrito na sequência.

\section{AMBIENTE DE AÇÃO DO PROJETO: CONTEXTOS E OS CONTATOS (CONFLITOS) LINGUÍSTICOS}

Para melhor ambientar o leitor sobre o contexto de pesquisa, serão abordados e descritos aspectos relacionados ao país, ao município e à comunidade em que está situada a escola, centrando especial atenção na questão linguística local e nacional que se refletem no educandário. Tais apontamentos são relevantes, pois, na pesquisa qualitativa, o contexto sócio-histórico precisa ser considerado a fim de interpretar os significados culturais. Por isso "[...] a pesquisa qualitativa procura entender, interpretar fenômenos sociais inseridos em um contexto" (BORTONI-RICARDO, 2008, p. 34), que pode ser a sala de aula, como neste estudo. Desse modo, a interpretação é feita por meio da análise de dados integrantes do ambiente focalizado, como os documentos, os registros e a própria prática docente.

Sob esse viés, é relevante discorrer sobre o espaço pesquisado, a começar por Ciudad del Este, que está localizada no extremo leste do Paraguai às margens do Rio Paraná, a $327 \mathrm{~km}$ de Asunción, capital do país. Destaca-se que faz fronteira com Foz do Iguaçu (Brasil) através da Ponte Internacional da Amizade, sobre o rio Paraná e com Puerto Iguazú (Argentina), com população de 367.310 habitantes, de acordo com dados da Dirección General de Estadística, Encuestas y Censos (DGEEC, 2011, p.75), é considerada a segunda cidade mais importante do país.

O município é conhecido, especialmente, porque recebe muitos turistas em busca do amplo comércio de eletrônicos e produtos importados. Além disso, existe trânsito de trabalhadores nos dois sentidos da ponte: paraguaios que trabalham em Foz do Iguaçu e brasileiros que atuam em Ciudad del Este. Destaca-se, ainda, que a referida cidade conta com número significativo de imigrantes chineses, libaneses, taiwaneses, entre outros. Devido a esse cenário diverso, há muitas línguas e culturas convivendo em sua zona comercial e bairros. Entretanto, salienta-se que o espanhol é a língua que prevalece sobre as línguas originárias nos ambientes de ensino formal, assim como ocorre frequentemente nos demais países da América-Latina, excetuando-se o Brasil, em que predomina o português.

O estabelecimento educativo público onde se desenvolvem as atividades do projeto acolhe estudantes de jardín, preescolar y nivel inicial com idade de 4 a 14 anos. A maioria das crianças do educandário é residente no próprio bairro em que está a escola. A fim de delinear o contexto social, econômico e linguístico, foi aplicado um questionário nos domicílios próximos à instituição. Verificou-se, então, que, embora as casas sejam razoavelmente grandes em estrutura, vivem nelas de 5 a 9 pessoas, atestando a alta densidade populacional da localidade. Constatou-se também que 45\% dos entrevistados concluíram o ensino médio, apenas 13\% 
superior e 40\% o básico. Tais dados revelam uma comunidade vulnerável do ponto de vista econômico e social e à margem de políticas de infraestrutura, saúde e educação.

Com relação ao conhecimento de línguas da citada comunidade, 54\% dos participantes afirmam falar guarani/jopará e castelhano, 18\% somente guarani/jopará, 13\% apenas castelhano e 13\% afirma falar tanto castelhano quanto guarani e citaram, ainda, o português. Ou seja, trata-se de um contexto plurilíngue.

Reconhece-se que, assim como os demais países latino-americanos, o Paraguai é um país multiétnico, pluricultural e plurilíngue, uma vez que a realidade cultural e linguística local é bastante heterogênea e dinâmica, envolvendo o uso de diferentes idiomas ou variedades linguísticas em diversas combinações, de forma complexa, a partir de questões sócio-históricas, ideológicas e geopolíticas. Há, no referido país, um total de 19 povos, pertencentes a cinco famílias linguísticas (DGEEC, 2011). Apenas 5\% da população é de origem indígena, sendo que, das 20 etnias indígenas presentes no país, seis pertencem à família guarani (Ache, $A v a$ Guaraní, Mbya, Pâi-Tavyterâ, Guaraní Nandéva y Guaraní Occidenta). Entretanto, estima-se, de acordo com o Censo (2002), que o guarani seja falado por $90 \%$ dos paraguaios, embora tal denominação abarque uma gama de variações linguísticas considerando a expressão oral da população. Nesse sentido,

[...] é importante observar que a língua guarani que está em questão no Paraguai é uma variante designada como guarani paraguaio, ou seja, não se trata da língua original, pré-hispânica. Mesmo porque, o chamado guarani tribal - utilizado ainda hoje por grupos indígenas remanescentes, como os Pai Tavyterã, Ava katu ete e Mbya constitui-se de uma multiplicidade de dialetos, o que inviabilizava sua utilização, pelos colonizadores, como língua geral para a comunicação com os colonizados. (PERES, 2001, p. 42)

Apesar da presença do falar guarani no país ser evidente, sua oficialização como língua nacional é de $1992^{5}$. Naquele momento, segundo as considerações de Peres (2001), intensificou-se a discussão a respeito de qual variedade da língua deveria ser utilizada pela escola: o jopará, guarani interferido pelo castelhano, utilizado comumente nas interações cotidianas; ou o guaraniete, considerado o guarani mais "puro", acadêmico, ou seja, a variedade estandartizada. Isso ocorreu dada a identificação do guarani como língua dos mais pobres, o que poderia provocar rejeições quanto à sua escolarização, pois a situação do país continua sendo de muita desigualdade social, desencadeando a presença da diglossia (PERES, 2001).

Em concordância com Hamel (1988), a diglossia é parte integrante de um conflito intercultural, a partir de aspectos sociolinguísticos que se manifestam em uma relação assimétrica das práticas discursivas dominantes com as práticas discursivas dominadas. $\mathrm{O}$ fenômeno da diglossia está relacionado a uma disputa de poder entre grupos sociais, sendo que a sociedade dominante tenta impor seus padrões de apropriação e interpretação por meio de diversas formas de comunicação. Retomando as ideias de Romaine (1996), concebe-se que as sociedades diglóssicas não se caracterizam somente pela alternância funcional de variedades ou línguas diferentes, mas pelas restrições que as situações impõem.

Nessa perspectiva, falar em interações desequilibradas nas relações entre línguas é falar de conflito linguístico, um termo usado para revelar a contradição da qual a relação entre as línguas faz parte, mesmo que possa aparecer de maneira velada ou sutil (HAMEL, 1988). Assim sendo, conflito linguístico não diz respeito a uma disputa entre línguas, mas sim ao aspecto linguístico de uma "luta" entre "[...] grupos diferenciados por fatores socioeconômicos, étnicos e/ou socioculturais" (HAMEL, 1988, p.52), sendo que as línguas dos colonizadores recorrentemente permanecem dominantes sobre as línguas das minorias locais. A esse respeito, Appel e Muysken (1996) citam que os membros de grupos sem prestígio social ou de minorias linguísticas, muitas vezes, têm a noção de que a língua usada por seu grupo não serve para alcançar ascensão social, tal fato, não obstante, não significa que os falantes não a tenham em consideração ou a abandonem. Nesse sentido, uma variedade ou língua menos prestigiada pode manter-se, pois está relacionada ao caráter de pertencimento ou identidade desses grupos. Por isso, segundo Hamel (1988), a questão não é tão simples, podendo causar uma confusão de sentimentos e comportamentos contraditórios, como será possível observar nas análises mais adiante.

No caso do Paraguai, um aspecto que merece atenção é, conforme Meliá (2012), a diferença de status social que o guarani tem em

${ }^{5}$ A Constituição de 1992 oficializa e generaliza não apenas o ensino de guarani mas, também, o ensino em guarani (PERES, 2001). 
relação ao espanhol, quando se trata do seu uso público, sendo que a prática mostra a diferença entre os dois falares, o segundo tendo mais espaço na cultura formal, nos meios de comunicação, no âmbito das tecnologias, enquanto o primeiro é tomado como a língua do cotidiano. Diante disso, o referido autor defende que a política do bilinguismo, chamada por ele de "ideologia do bilinguismo", conduz à "castellanización”, que seria a aceitação e a aprendizagem do espanhol pelos guarani-falantes, já o processo contrário não acontece. Nesse sentido, há mais a substituição de uma língua pela outra do que a interculturalidade real entre as línguas e os sistemas de vida.

A respeito do assunto, Peres (2001) destaca que o fato de um terço das crianças paraguaias ser monolíngue em guarani é visto com preocupação e como fator determinante de baixa qualidade da educação. Por outro lado, a existência de outro terço monolíngue em castelhano não é considerada dessa mesma forma. O insucesso escolar estaria, dessa forma, atrelado apenas ao saber da língua de origem indígena e não da língua de origem europeia.

Verifica-se, diante dessas discussões, que o contato entre as línguas não acontece sem conflito, porque quando ocorre uma situação de contato, a língua identificada com um grupo de menor poder político, econômico e cultural terá o status de língua minoritária ${ }^{6}$ ou estigmatizada, contrastando com a língua majoritária ou de prestígio. A partir dessa constatação, retoma-se as palavras de Altenhofen (2013, p. 95): “[...] a discriminação que normalmente se associa às línguas minoritárias não é inerente à língua e à sua definição, mas sim reflete uma situação social vigente que demanda justamente de uma política e de um planejamento linguístico, para resolver conflitos e disparidades".

Por conseguinte, o que há nos documentos oficiais e nas práticas escolares, recorrentemente, é o prestígio da língua espanhola como símbolo do progresso econômico e a educação formal, e o guarani, como uma parte da identidade nacional, mas ocupando um espaço de menor prestígio social. Além disso, o distanciamento do falar guarani da comunidade com a variedade presente nos livros didáticos faz com que muitos alunos avaliem negativamente seu conhecimento da língua, sem reconhecer o guarani escolar, mas considerando este último como o "verdadeiro". Conforme Peres (2001), comumente, os afastamentos do guarani, considerado padrão, são vistos como incorreções, um "guarani errado", então, muitos alunos paraguaios consideram que falam "mal” o guarani ou que não sabem a língua.

Essa crença de que o jopara é um guarani errado é um dos fatores que, paradoxalmente, desperta descontentamento com a escolarização da língua guarani: por que não aprender logo o castelhano, que é mais útil, em lugar de aprender um guarani correto que não é o utilizado no cotidiano? Para a fala cotidiana, o jopara, mesmo sendo um guarani errado, é suficiente. Ademais, a simplicidade e a facilidade do jopara desaparecem quando se trata de aprender o guarani acadêmico. (PERES, 2001, p. 50)

Diante desse cenário, a importância dada pelos membros de uma sociedade ao fato de se usar a variedade adequada no contexto adequado é característico da diglossia. A questão conflituosa surge quando os habitantes consideram a variedade alta superior à outra ou às demais (ROMAINE, 1996), assim, aquele que usa uma variedade baixa em contexto inadequado poderá ser estigmatizado. Tal situação pode provocar a baixa autoestima linguística e a inviabilização da língua materna do falante diante de sua negação.

A discussão acerca dos conflitos linguísticos no Paraguai pode ser observada pela interação entre mediadores de leitura e o grupo de estudantes e, para estabelecer a conversa exigida pela prática de leitura literária, é importante conhecer os falares em contextos oficiais, familiares e informais.

\footnotetext{
${ }^{6}$ Sobre o conceito de língua minoritária, Hornberger (1998) focaliza os conceitos minoria versus maioria e afirma que essa distinção está mais relacionada ao poder e ao prestígio do que a quantidade de falantes (números).
} 


\section{REFLEXÕES DAS PERCEPÇÕES E PRÁTICAS DISCENTES POR MEIO DE UMA ATIVIDADE COM MEDIAÇÃO DE LEITURA}

Diante do desafio instaurado e movidos pelo desejo de entender como seria a mediação de leitura em um grupo de alunos que informava com determinação a necessidade de uma relação mais horizontal, para que mediadores e interlocutores falassem a "mesma língua", a equipe do projeto elaborou um plano de trabalho que tinha como pressuposto: "Nós não sabemos guarani, mas podemos compartilhar diversas histórias com vocês, então podemos ler juntos e vocês, ao mesmo tempo, nos ensinam sua língua". Por este raciocínio, entendeu-se que estaria estabelecida uma relação mais próxima daquilo que teóricos advogam como mediação cultural/intercultural (MENDES, 2004; CANCLINI, 2004). Nesta perspectiva, compreende-se que a mediação de leitura ao colocar em evidência a dimensão socializadora da literatura tem potencial para proporcionar momentos de troca de saberes e diálogos interculturais que possam contribuir para promover a sensibilização, o reconhecimento da alteridade, a valorização da diversidade étnica e cultural e a integração.

É pertinente esclarecer que desde 2018 foram realizadas práticas de mediação de leitura já no espaço bibliotecário (inaugurado em 2018) do educandário paraguaio pesquisado. Inicialmente, para conhecer os estudantes, selecionou-se um grupo de $1^{\circ}$ grado com crianças de 6 a 8 anos para desenvolver práticas de leitura continuadas durante o $2^{\circ}$ Semestre de 2018 e $1^{\circ}$ Semestre de 2019 . Ressaltase que as visitas às escolas são semanais, acontecendo sempre às quartas-feiras. A pedido da direção, no $1^{\circ}$ Semestre de 2019 , foram ampliadas as atividades a todos os grupos do período matutino, contudo, a ação, neste caso, foi pontual, ou seja, houve apenas um encontro com o grupo de educação infantil e com os $2^{\circ}, 3^{\circ}, 4^{\circ}$ e $5^{\circ}$ grados. Nesta mediação literária, foi feita a leitura em voz alta e compartilhada da obra Cosita Linda, de Anthony Browne, quando houve a situação de conflito inicial com a turma do $5^{\circ}$ Ano. Para a continuação do trabalho, foi desenvolvido um plano de ação com o seguinte objetivo: "Por meio de um projeto de leitura compartilhada de cinco contos de Horácio Quiroga, as mediadoras e as crianças criariam, em pequenos grupos, um conto ilustrado em espanhol e guarani”.

Optou-se, durante este novo plano, fazer perguntas, algumas mais específicas (em torno dos conhecimentos e contatos linguísticos do grupo) e outras não, durante uma atividade de mediação ${ }^{7}$. Para tanto, selecionou-se o livro Para nombrar el mundo, de Andrea Fuentes Silva e Alejandro Cruz Atienza, de nacionalidade mexicana, que pareceu oportuno, porque elenca algumas palavras que são apresentadas em espanhol e outras sete línguas indígenas do país.

No decorrer da atividade, no entanto, como é natural em sala de aula, lidou-se com imprevistos e improvisos durante a sua execução. Então, para este estudo, o relato da interação ${ }^{8}$ foi dividido em três momentos significativos para levantar dados sobre aspectos linguísticos da turma, ou seja, para sondar seus conhecimentos e contatos com as línguas, bem como avaliações e práticas sobre aquelas: 1) sondagem inicial: enquanto a professora regente da turma liberava as crianças para a atividade na biblioteca, as mediadoras as receberam com uma conversa informal que abordou, predominantemente, questões em torno de conhecimentos sobre as línguas; 2) perguntas dirigidas: cada uma das crianças tirou uma pergunta do "potinho" e a respondeu supostamente para um estudante de uma cidade o Brasil. Além disso, a comanda solicitava que os discentes participantes se apresentassem à medida que respondiam as questões propostas; e 3) leitura e tradução: o livro foi apresentado e participantes voluntários se dirigiam até a lousa e registravam a palavra que completaria o quadro linguístico de língua mexicanas com uma palavra equivalente em guarani.

\section{1) Sondagem inicial ${ }^{9}$}

Como nem todos os alunos chegaram juntos, foi estabelecida uma longa conversa prévia descontraída e menos dirigida, porém, o

\footnotetext{
${ }^{7}$ Inicialmente, a ideia era elaborar um questionário (semiestruturado) que seria aplicado individualmente aos alunos pela equipe. Contudo, as mediadoras não se sentiram seguras com esta proposta, pois entendiam que as perguntas eram difíceis para as crianças e, além disso, não se sentiam confortáveis com aquele espaço plurilíngue, previamente identificado.

${ }^{8}$ Ressalta-se que apenas as interlocuções que contribuam com os aspectos trabalhados por este artigo serão descritas e analisadas.

${ }^{9}$ Para os diálogos dispostos na sequência deste estudo, serão utilizadas as iniciais M - para mediadoras (M1 e M2) e A (1,2,3..) - para os alunos que se manifestaram. Destaca-se que a transcrição foi traduzida para o português para esta análise.
} 
intuito já era a aproximação do alunado ao assunto proposto acerca do conhecimento em torno das línguas. Destaca-se que as crianças falam baixo e, muitas vezes, a mediadora 1 (M1) pede para que repitam seu comentário. Claramente, nota-se que há dificuldade de compreensão entre os interlocutore ${ }^{10}$, sendo comuns as situações em que a M1 não entende e não consegue dar continuidade à conversa. A estratégia utilizada por ela, recorrentemente, é retomar parte do que foi falado e entendido na resposta em voz alta, para que os outros alunos deem sequência ao diálogo ou expliquem a resposta do colega.

Logo no início desta etapa do projeto, M1, que não estava participando ativamente nos encontros, faz, naquele momento, uma série de perguntas sobre as leituras compartilhadas no tempo em que não esteve presente. Os estudantes lembram de algumas histórias contadas naquele período e M1 dá continuidade à conversa, afirmando que soube que os alunos estavam ensinando guarani para as mediadoras. Neste momento, os discentes apressam-se em apontar um deles (A1), manifestando que ele tem "total" domínio do idioma. A partir disso, M1 aproveita para indagar:

M1 - Ah, e ele fala "bem" guarani?

Em coro, os discentes afirmam que sim.

M1 - E alguém mais fala o guarani?

A2 - Alguns sabem e outros não sabem muito.

Uma das meninas pede a palavra e afirma que fala.

M1 - Você fala guarani desde pequena?

A3 - Sim.

M1 - Na sua casa?

Ela afirma que sim com a cabeça,

M1 - E com quem você fala em guarani na sua casa?

A3 - Com minha irmãzinha.

M1 tenta verificar se a língua é usada com outras pessoas da família da A3 - avó (já morreu), tia (mora longe). Então, pergunta:

M1 - E você ensina o guarani para sua irmãzinha?

A3 - Não, ela já sabe.

M1 - E onde você aprendeu guarani?

A3 - Sozinha.

Nesta situação relatada, constata-se que a noção da aquisição da língua guarani pelas crianças é vista como natural, simplesmente a irmãzinha "já sabe” e a discente "aprendeu sozinha”, ou seja, não é uma língua de instrução escolar, de educação formal, mas está intrínseca ao cotidiano delas, fazendo parte de suas vivências no contexto do lar.

Além disso, quando os discentes afirmam que um colega tem o domínio "total" da língua guarani revelam que entendem que há diferenças entre os conhecimentos deles sobre esse falar, sendo que a proficiência maior do colega é notada por eles. Há, assim, uma diferença entre os falares que os discentes possuem, como destacou A2 "Alguns sabem e outros não sabem muito", além da percepção de que para falar bem um idioma é preciso conhecê-lo totalmente.

A mediadora 1, a partir da resposta de A3, questiona outro estudante:

M1 - Você fala guarani em casa?

A4 responde que não e, na sequência, M1 complementa:

M1 - E na sua casa?

A4 responde que também não, afirmando que só fala na escola. A5 então pede a palavra e explica que eles utilizam a língua guarani somente para ler na escola. M1 não se satisfaz com essa resposta e interroga:

M1 - E o aluno A1? Ele sim fala desde pequeno?

E ele responde que sim.

${ }^{10}$ Duas hipóteses podem ser aventadas a respeito disso: 1) timidez e falta de confiança para falar ou 2) a incompreensão se dá por “desencontros” linguísticos. 
Neste caso, pode-se inferir que a língua guarani está presente na vida dos discentes de diferentes maneiras, para alguns é uma língua presente na família e para outros seu uso fica mais restrito à escola, na disciplina específica, por isso aparece a fala do uso do guarani para "leitura", ou seja, as crianças recebem aulas "sobre guarani" (PERES, 2001). A respeito dessa forma de educação bilíngue, Meliá (2012) atenta para o fato de que o contato entre as duas línguas, espanhol e o guarani, dentro da sala de aula, pouco ou nada favorecem o intercâmbio ou uma interculturalidade, uma vez que cada uma das línguas representa valores diferentes, não havendo uma ligação total, são os guaranis falantes que passam a ser bilíngues. "Aqui é onde se faz patente a falta de interculturalidade entre línguas e sistemas de vida, que apenas entra como prótese incomoda e ao final rejeitada” (MELIÁ, 2012, p. 93).

Na continuidade da interação, a mediadora 1 vai em direção a outras crianças que estão falando, entre si, em guarani (notase que ela reconhece a língua ${ }^{11}$ ) do outro lado da roda e afirma:

M1 - Vocês estão falando em guarani. Por quê? (achando graça). Ah, por que assim eu não entendo, não é?! (em tom irônico).

Verifica-se que a mediadora 1 revela um conhecimento prévio da relação linguística estabelecida entre eles, pois se sente excluída linguisticamente do diálogo. O grupo de discentes entende a situação irônica exposta e ri.

Na sequência, a mediadora 1 diz:

M1 - Ah, entendi! Alguns falam em guarani e outros em castelhano!

E, ainda, questiona de maneira geral para todos os participantes:

M1 - E como vocês se entendem?

Uma das alunas responde:

A6 - Entendendo!

Constata-se, a partir dessa afirmação, que as crianças não se preocupam em estabelecer no diálogo entre eles uma divisão entre os idiomas, uma vez que há compreensão nas interações estabelecidas. A respeito deste aspecto, Cañete et al. (2014, p. 34) esclarecem “[...] De esto se puede colegir que los hablantes saben 'lo necesario' de cada lengua para poder emitir un mensaje con sentido para el otro. La delimitación propia en el sentido de límites y coherencia interna exige que los interlocutores compartan las normas y las 'licencias admitidas' que garanticen la comunicabilidad" 12 .

Observa-se, durante todo o contato com eles, que os discentes interagem de várias formas em momentos diferentes, alternando as línguas e mesclando-as, principalmente quando estão falando de assuntos não escolares, em conversas mais informais, usando o guarani ou jopará. Por meio das considerações de Demelenne (2007), retoma-se o desafio do modelo de educação bilíngue naquele país, como já citado por outros autores, uma vez que as crianças estão inseridas em contextos plurilíngues e transitam entre essas línguas tornando-as funcionais em suas diversas práticas.

Outra observação pertinente a ser destacada é que os alunos agora demonstram ter bastante sensibilidade ao se dirigir às mediadoras sempre em espanhol quando participam das atividades relacionadas ao projeto, usando com elas o guarani apenas quando solicitados, como acontecerá numa atividade descrita mais adiante.

Na continuidade da interação, ainda acerca do tópico em torno de quem sabe falar guarani, a colega ao lado de A3, que afirmou anteriormente saber, se anima e relata que também interage em guarani com todos da sua casa. Outra aluna cita que fala em guarani e em castelhano e que em sua casa são usados os dois idiomas. Mais um aluno, do outro lado da roda, afirma que fala guarani e que aprendeu com seu pai e com sua mãe. Com essa situação, verifica-se que não há como saber exatamente quantos discentes falam o guarani como língua materna ou quantos aprenderam espanhol e guarani juntos em casa, mas, nitidamente, este falar faz parte do

\footnotetext{
${ }^{11}$ Vale notar que mesmo para falantes de espanhol como segunda língua, como a mediadora principal (M1), não é fácil distinguir a língua que as crianças estão utilizando, principalmente quando estão falando entre elas.

12 “A partir disso, pode-se inferir que os falantes sabem 'o que é necessário' de cada língua para emitir uma mensagem com sentido para o outro. A delimitação própria no sentido de limites e coerência interna exige que os interlocutores compartilhem as normas e as 'licenças admitidas' que garantam a comunicabilidade” (Tradução nossa).
} 
cotidiano das crianças e, quando observam que os colegas acenam positivamente para esse conhecimento, os demais se sentem confortáveis e estimulados para sinalizarem que sabem. Ao observar a cena, verifica-se que todos estão concentrados e interessados no assunto, mostrando interesse em escutar e participar da conversa, ou seja, é um assunto com o qual se identificam.

Constata-se, a partir disso, como os falantes influenciam e são influenciados pelas práticas sociais das quais fazem parte, inclusive quando se discute a ideia de sentimentos linguísticos sobre as línguas, sobre a valorização e a desvalorização das formas linguísticas nos diversos contextos de uso (MORENO FERNÁNDEZ, 1998). Assim, o falar guarani é recorrente entre os falantes, mas nem sempre assumido para outros que não fazem parte desse grupo.

É possível, então, afirmar que existe a presença de duas línguas e que uma delas, às vezes, é revelada ao “outro" e outras vezes não, vai depender da cumplicidade estabelecida, evidenciando que há, nesse espaço, um conflito, um contexto diglóssico, como apontado anteriormente. Há, portanto, dois comportamentos distintos ao se indagar sobre o saber guarani, pois quando as crianças são interrogadas diretamente, pelo exemplo analisado, elas não respondem afirmativamente sobre seu conhecimento linguístico, revelando uma atitude negativa inicial, porém, quando há o estímulo entre os atores da interação, os estudantes se sentem mais à vontade para compartilhar seus saberes de forma positiva.

\section{2) Perguntas dirigidas}

Com a intenção de saber mais acerca das práticas e conhecimentos linguísticos dos discentes, na sequência, foi introduzida uma dinâmica com perguntas dirigidas. Para tanto, eles foram instigados a responder questionamentos a partir da seguinte comanda "Alunos de outra cidade querem conhecer vocês e fizeram algumas questões que estão aqui no potinho, cada um vai sortear uma e vamos filmar as respostas para levar para eles”. A dinâmica muda o grau de confiança, porque neste momento os discentes são convidados a expor-se e a "apropriar-se" de quem são.

Os alunos seguem em roda e cada um sorteia uma pergunta elaborada pela equipe. Uma das perguntas é:

M1 - Quais idiomas você fala?

Com muita rapidez e autoridade, um aluno diz:

A5 - Castelhano, guarani, português e..... como se diz argentino? Eu sei falar argentino, mas não sei.... (provavelmente o nome do idioma). M1 continua o diálogo:

M1 - E como aprendeu tantas línguas?

A3 - Quando viajei para lá, já aprendi.

Este posicionamento do discente A3 revela que ele entende a distinção entre os falares espanhol de diferentes lugares, mesmo sem conseguir dar um nome para essa diferença, mas compreendendo que ela existe, ou seja, não é o mesmo espanhol do Paraguai, podendo ser, inclusive, compreendido como um outro idioma. Ao mesmo tempo, o discente relaciona a língua a um país, assim, na Argentina se fala argentino, atitude que reafirma a política oficial de Estado, como abordado nos aspectos teóricos deste trabalho.

É significativo destacar que os estudantes desta escola, com muita frequência, trabalham no comércio de Ciudad del Este, como já mencionado, sendo que na região circulam muitos visitantes dos países da faixa de fronteira, por isso se observa que o aluno cita precisamente as línguas do Brasil e da Argentina, que estão mais próximas do seu contexto.

A questão seguinte foi:

M1 - O que você gostaria de aprender?

Rapidamente, com muita assertividade, o estudante diz:

A6 - O guarani!

A partir da pronta resposta, nota-se o desejo do discente e de outros que agora também declaram ter vontade de conhecer mais 
aquela língua que já está presente, mas que, muitas vezes, não é reconhecida, pois acreditam não saber falar, mesmo falando. É possível aventar que alguns têm mais proximidade com a língua guarani, como já foi mencionado, e outros gostariam de saber mais.

Observa-se que o discente em questão, A6, foi apontado pelo grupo como aquele que não sabe ler, relacionando essa afirmação com aquela dada por outra colega de que eles apenas têm aulas de leitura em guarani, é possível inferir que o estudante A6 considera que não sabe guarani porque não sabe ler, ou seja, porque não possui o conhecimento escolarizado da língua, que seria considerado o "verdadeiro" conhecimento, como já citado.

Na sequência dos sorteios das perguntas mais dirigidas, em outra interação, A1, que é aquele apontado pelos colegas como o que "mais fala guarani", também pede ajuda do colega ao lado para ler a pergunta em espanhol. A pergunta era:

M1 - Quando tiver filhos, que idioma vai falar com eles?

Com muita precisão, ele responde:

Al - Guarani!

Esse querer ensinar mostra uma atitude positiva de A1 com relação à língua guarani falada por ele. Sobre o assunto, Grosjean (2001) menciona que as atitudes ou os posicionamentos em relação à língua refletem as atitudes ou os posicionamentos em relação aos usuários dela, provocando emoções que vão da lealdade à aversão linguística, sendo, em parte, responsáveis pela manutenção ou pela mudança linguística. O Aluno 1, pela resposta e sinalização de comportamento, prima pela manutenção, uma vez que afirma o desejo de querer ensinar aquela língua para seus filhos. A1, assim, assume seu conhecimento e uso da língua, entendendo-a como marca identitária. Depreende-se que, para ele, este saber é valorizado a tal ponto que pretende perpetuá-lo.

Nesse sentido, podem-se retomar aspectos sobre políticas linguísticas oficiais, como a existência da lei, as quais não garantem uma ação se não houver um trabalho efetivo de conscientização linguística (language awareness) por meio de projetos que, entre outras medidas, assessorem pais na decisão de que línguas ensinar aos filhos, sendo instruídos em torno dos benefícios do bilinguismo, bem como criando uma imagem positiva a respeito da língua minoritária (ALTENHOFEN, 2013). Sob este viés, constata-se que a maioria dos estudantes, diferentemente do A1, pelo menos de início, não possui um posicionamento de valorização do guarani ou, ainda, que há diferentes valorações a respeito desse idioma.

\section{3) Leitura e Tradução}

A proposta seguinte foi, a partir da leitura compartilhada do livro mexicano, Palabras para nombrar el mundo, de Andrea Fuente Silva e Alejandro Cruz Atienza, editora La caja de Cerillos, que apresentava palavras em espanhol e em mais sete línguas indígenas (Maya, Mixteco, Náhualt, Ramámuli, Tseltal, Wixárika e Zapoteco). A mediação tinha como objetivo ampliar o "vocabulário" apresentado pelo livro, registrando na lousa, coletivamente, o mesmo vocábulo (espanhol) em guarani. A ideia era verificar quais os estudantes que participariam da tradução e de que maneira apresentariam seus conhecimentos linguísticos.

Já no início do desafio, os discentes notam que muitas palavras são iguais em espanhol e em guarani, por exemplo - mundo, norte, sur etc. Uma das mediadoras (M2), que é paraguaia e tem o guarani como língua materna, explica, diante disso, que efetivamente muitas palavras são iguais nos dois idiomas.

Entretanto, verificou-se que M2 se mostra, algumas vezes, incomodada com o fato de as crianças não fazerem bem a "tradução" ou escrevê-las de maneira "errada" na lousa. Ela inclusive corrige a grafia registrada pelas crianças no quadro. A atitude de M2 pode ser interpretada como a valorização da língua guarani em sua versão estandardizada, focalizada na política oficial de ensino da escola pela qual deve ter passado. Como consequência, pode-se pensar que essa postura reforça a escolarização sobre o guarani presente no educandário e, assim, o distanciamento desse conhecimento por parte dos discentes que precisam ser corrigidos para aprender o "certo", ou seja, a variedade standard.

Além disso, corroborando os dados extraídos da mediação, logo que a equipe do projeto chegou à escola já notou que nas salas de aula há presença das duas línguas escritas na nomeação de objetos, como na porta, janela e quadro negro. Nos cartazes dispostos na 
sala de aula, está a palavra em espanhol e, logo abaixo, a mesma em guarani, como uma forma de fixar uma "língua estrangeira" ou como exercício de alfabetização. Também existem propagandas e informes, localizados dentro e fora das salas, que estão apenas na língua espanhola, o que reforça que o discurso oficial permanece na língua de maior prestígio social. Ademais, esse comportamento de apenas traduzir as designações do objetos, a partir de duas línguas bem delimitadas, com padrões de correção, como verificado na atitude de uma das mediadoras, revela a valoração da forma escrita. Um pouco deste cenário pode ser verificado na imagem disposta na sequência:

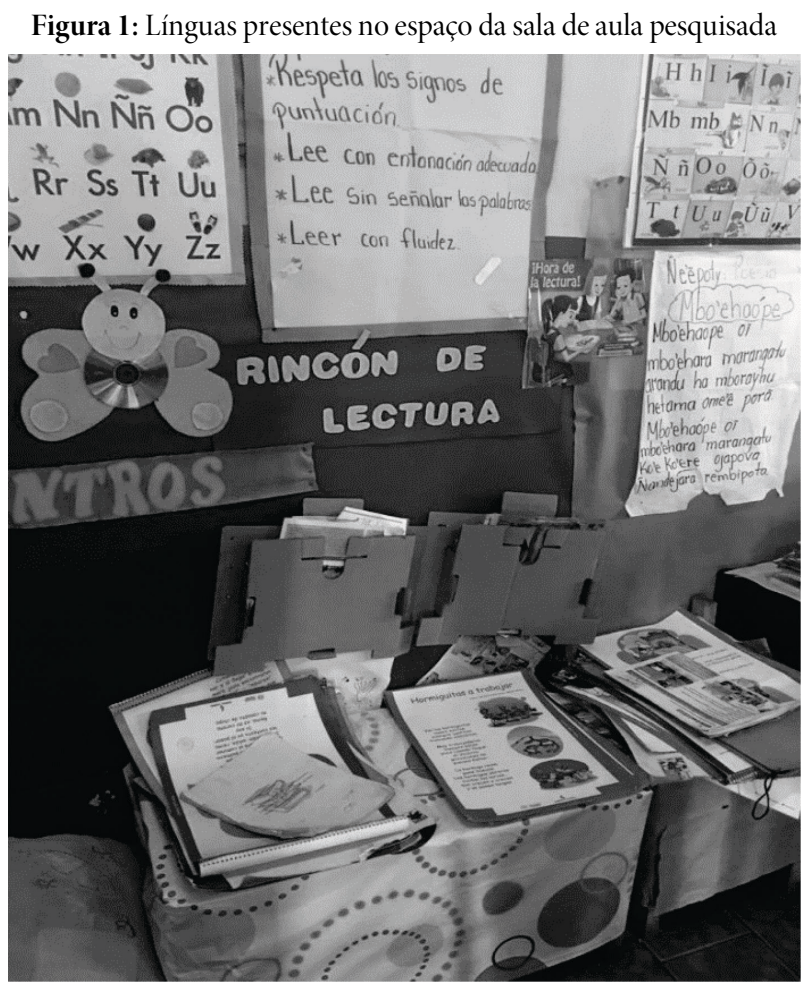

Fonte: Dados da pesquisa (2019)

Vale ressaltar, ainda, que a língua que sempre aparece em primeiro na nomeação dos objetos e cartazes é o espanhol.

Ainda durante a sessão, as crianças manifestaram interesse em participar e escrever as palavras na lousa. Uma das alunas, A2, aquela que havia dito, no início da interação, que não falava guarani, foi a que mais prontamente respondeu no idioma. Ademais, o aluno que dizia que seu desejo era aprender guarani, A6, quando aparece a palavra "lua”, para ser traduzida, as crianças dizem "yaci” e ele, em tom de brincadeira diz "yaci yatere", que é um personagem folclórico na cultura paraguaia. Mais uma vez, verifica-se o conhecimento dos discentes de aspectos culturais e linguísticos em torno do guarani que, muitas vezes, são negados e, em outros momentos, como foi visto, enaltecidos. São subjetivações complexas, uma vez que as atitudes são, conforme já citado, de ordem social, mas também psicológicas e influenciadas pelo contexto de interação (MORENO FERNÁNDEZ, 1998). Até porque, naquele momento, os alunos estavam mais descontraídos e focados na atividade.

\section{ALGUMAS CONSIDERAÇÕES}

Diante das considerações feitas ao longo deste texto, constata-se que todo fenômeno linguístico é amplo e complexo, sendo um desafio sua compreensão. No entanto, a partir dos dados levantados e das reflexões desenvolvidas ao longo desta pesquisa, serão feitos alguns apontamentos em torno das práticas e percepções linguísticas dos discentes.

Verificou-se que os falantes da língua minoritária, guarani/jopará, apresentam-se como o grupo mais afetado pelas atitudes, revelando comportamentos contraditórios em relação à língua de menor status social naquele espaço, alternando posicionamentos às vezes favoráveis e às vezes menos favoráveis a esse falar. As consequências vão de encontro à crença de que, mesmo sendo falantes 
(fato confirmado nas conversas informais e na atividade de mediação final), afirmam não conhecer bem a língua, ou mesmo, manifestam a negação desse conhecimento, revelando um conflito estabelecido entre as línguas em contato.

Diante disso, constata-se que a inserção do guarani como língua oficial no país e na educação paraguaia, como uma política oficial, nem sempre gera sua valorização, dando a impressão que se tem, pelo menos no estudo dessa instituição, duas línguas guaranis: a de casa e a da escola, a primeira, quando reconhecida pelos discentes, é vista como natural, e a segunda, por vezes, considerada distante deles.

Por outro lado, pelo viés das condutas de ordem afetiva, depreende-se uma consequência positiva quando há a manifestação dos discentes para o reforço da lealdade e da solidariedade do grupo desprestigiado quando vários deles assumem conhecer a língua guarani, um após o outro. Nota-se, por exemplo, uma clara divisão na sala entre os discentes que conhecem mais o guarani e, por isso, ficam mais próximos, e os que conhecem menos e que ficam mais entre eles. Ou seja, a língua, como constituição da identidade social do indivíduo, aparece como fator de inclusão ou de exclusão, como foi exposto na tensão inicial da mediação realizada com a turma ou quando os alunos falam entre eles para que o terceiro, não pertencente ao grupo, não entenda.

Então, apesar de parte dos discentes reconhecer que o guarani faz parte de suas vivências e experiências, os alunos possuem a tendência inicial de declarar que usam mais ou que conhecem mais o espanhol, por ela ser considerada a língua de prestígio naquele ambiente. Assim, embora haja a presença de ambas as línguas nos diálogos e até no ensino formal, como foi visto, cada uma assume papeis e usos diferentes a depender do contexto e do tipo de atividade proposta. Nesse sentido, pode-se perceber que as marcas que algumas vezes estigmatizam também identificam o grupo, como os que manifestaram querer ensinar os filhos, uma atitude positiva que enfatiza o desejo de perpetuar seu conhecimento.

Tal cenário "desparelho" e conflituoso coloca em evidência a complexidade de um cenário intercultural no que diz respeito às disputas, aos atravessamentos de relações de poder entre seus participantes e ao papel dos gestores que podem ainda ter posturas baseadas em uma visão restrita sobre o papel que as línguas podem assumir nesses contextos plurilíngues. Por isso, há a necessidade de olhar atento por parte dos mediadores externos para com esses ambientes a fim de não reafirmar atitudes preconceituosas com relação aos falares e, consequentemente, aos seus falantes.

Além disso, notou-se que, ao longo do processo, o grupo de discentes estabeleceu um laço de confiança e aquela tensão verificada na mediação pontual, inicialmente relatada neste texto, já não existe. Nas considerações de Coracini (2007), a aceitação do diferente passa, necessariamente, pela experiência do estranhamento, sendo que, para tanto, o professor necessita estar preparado para conduzir essa aceitação. Nos contextos educacionais, os contatos entre falantes de diferentes línguas evidenciam esse "encontro com o diferente" (SILVA, 2000), sendo comum conflitos e tensões iniciais.

Ressalta-se, por fim, que os movimentos em torno de políticas de educação linguística sobre as línguas minoritárias, mesmo que tenham tido mais espaço nos últimos anos nos estudos da Educação, ainda precisam ser aprofundados para que situações que envolvam cenários sociolinguisticamente complexos, como o descrito neste estudo, sejam tratados de forma mais sensível e abarquem de maneira positiva diferentes línguas e culturas e, assim, seus usuários.

\section{REFERÊNCIAS}

ALTENHOFEN, C. V. Política lingüística, mitos e concepções lingüísticas em áreas bilíngües de imigrantes (alemães) no Sul do Brasil. Revista Ibero Americana, v. 2, n. 1, 2004, p. 83-93. Disponível em: http://www.ibero-americana.net/files/ejemplo_por.pdf. Acesso em: 15 jan. 2012.

ALTENHOFEN, C. V. Bases para uma política linguística das línguas minoritárias no Brasil. In: NICOLAIDES, C. et al. (org.). Política e Políticas Linguísticas. Campinas: Pontes Editores, 2013, p. 93-116.

APPEL, R.; MUYSKEN, P. Bilingüismo y contacto de lenguas. Barcelona: Ariel, 1996. 
BORTONI-RICARDO, S. M. O professor pesquisador. Introdução à pesquisa qualitativa. São Paulo: Parábola, 2008.

BOTASSINI, J. O. M. A Importância dos Estudos de Crenças e Atitudes para a Sociolinguística. SIGNUM: Estud. Ling., Londrina, n. 18, v. 1, p. 102-131, jun. 2015. Disponível em: http://www.uel.br/revistas/uel/index.php/signum/article/view/20327. Acesso em: 15 jan. 2020.

CALVET, L. J. Sociolinguística: uma introdução crítica. Tradução de Marcos Marcionilo. São Paulo: Parábola, 2002.

CALVET, L. J. As políticas lingüísticas. Tradução de Isabel de Oliveira Duarte, Jonas Tenfen e Marcos Bagno. São Paulo: Parábola, 2007.

CANCLINI, N. G. Diferentes, desiguales y desconectados. Mapas de la Interculturalidad. Barcelona, Espanha: Gedisa, 2004.

CAÑETE, A. et al. La lengua guaraní en el sistema educativo en las últimas dos décadas. Asunción, Paraguay: Ministerio de Educación y Ciencias, 2014.

CAVALCANTI, M. C. Estudos sobre Educação Bilíngüe e escolarização em contextos de minorias lingüisticas no brasil. D.E.L.T.A., v. 15, n. Especial, 1999, p. 385-417. Disponível em: http://www.scielo.br/pdf/delta/v15nspe/4023.pdf. Acesso em: 25 mar. 2020.

CONSTITUCION NACIONAL. Congreso Nacional de la Asunción. Asunción, 1992.

CORACINI, M. J. A celebração do outro: arquivo memória e identidade: línguas (materna e estrangeira), plurilinguismo e tradução. Campinas, SP: Mercado de Letras, 2007.

CORVALÁN, G. Estado del arte del bilingüismo en América Latina. Asunción: Centro Paraguayo Estudios Sociológicos, 1985.

DEMELENNE, D. Educación bilingüe en Paraguay como ejemplo de transformación de las prácticas de enseñanza en un contexto pluricultural. Educ. foco, Juiz de Fora, v. 12, n. 2, fev. 2008, p. 01-18.

DGEEC. Dirección General de Estadísticas, Encuestas y Censos. Atlas de las comunidades indigenas en el Paraguay. II Censo Nacional Indígena de la población y viviendas 2002. 2004.

GROSJEAN, F. Life with two languages: an introduction to bilingualism. 11. ed. Cambridge, Massachusetts/London: Harvard University Press, 2001.

HAMEL, R. E. La política del lenguaje y el conflicto interétnico: problemas de investigación sociolingüística. In: ORLANDI, E. Política Lingüística na América Latina. Campinas. São Paulo: Pontes, 1988. p. 41-73.

HORNBERGER, N. H. Language policy, language education, language rights: Indigenous, immigrant and international perspectives. Language in Society, v. 27, n. 2, p. 439-458, 1998 . Disponível em: https://repository.upenn.edu/cgi/viewcontent.cgi?article=1273\&context=gse pubs. Acesso em: 20 jan. 2020.

HAMEL, R. E. Políticas del lenguaje y educación indígena em México. Orientaciones culturales y estrategias pedagógicas em una época de globalización. In: BEIN, R.; BORN, J. Politicas lingüísticas - norma e identidad. Argentina: Universidad de Buenos Aires, 2001, p. 143-170. 
LÜDKE, M.; ANDRÉ, M. E. D. A. Pesquisa em educação: Abordagens qualitativas. São Paulo: EPU, 1986.

MAHER, T. M. Ecos de resistência: políticas linguísticas e línguas minoritárias no Brasil. In: NICOLAIDES et al. (org.). Política e políticas linguísticas. Campinas, SP: Pontes Editores, 2013, p. 117-134.

MELIÁ, B. Pueblos Indígenas en el Paraguay: Demografía histórica y análisis de los resultados del Censo Nacional de Población y Viviendas 1992. DGEEC, Fernando de la Mora, 1997.

MELIÁ, B. La interculturalidad y la farsa del bilinguismo. Abeache. Revista da Associação Brasileira de Hispanistas, v. 2, n. 2. São Paulo: ABH, p. 89-94, $1^{\circ}$ semestre, 2012. Disponível em: http://www.hispanistas.org.br/arquivos/revistas/sumario/revista2/8994.pdf. Acesso em: 03 jan. 2020.

MENDES, E. Abordagem Comunicativa Intercultural: uma proposta para ensinar e aprender língua no diálogo de culturas. 2004. 432 f. Tese (Doutorado em Linguística Aplicada da Universidade Estadual de Campinas) - UNICAMP/SP. São Paulo, 2004.

MORENO FERNÁNDEZ, F. Princípios de Sociolingüística y sociología del lenguaje. Barcelona: Ariel, 1998.

PENNER, H. Efectos de la escritura(liza)ción del guaraní por y para no guaranihablantes. In: RODRIGUES J. (org.). Ciudadania democratica y multilinguismo: La construccion de La identidad linguistica y cultural del Mercosur. Asuncion, 2012. p. $129-146$.

PERES, S. Avañe'e, ñe’e tavy, karai ñe’e: escolarização do guarani e diglossia no Paraguai. Revista Histórica da Educação, v. 5, n. 9, p. 39-58, jan./jun. 2001. Disponível em: https://seer.ufrgs.br/asphe/article/view/30407. Acesso em: 10 dezembro 2019.

RAJAGOPALAN, K. A norma linguística do ponto de vista da política linguística. In: LAGARES, X. C.; BAGNO, M. (org.). Políticas da norma e conflitos linguísticos. São Paulo: Parábola Editorial, 2011.p. 121-128.

RAJAGOPALAN, K. Política linguística: do que é que se trata, afinal? In: NICOLAIDES, C. et al. (org.). Política e políticas linguísticas. Campinas, SP: Pontes Editores, 2013. p. 19-42.

ROMAINE, S. El lenguaje en la sociedad: una introducción a la sociolingüística. Barcelona: ARIEL, 1996.

SCHIFFMAN, H. Language Policy and Linguistic Culture. In: RICENTO, T. (ed.). An introduction to language policy: Theory and method. Oxford: Blackwell Publishing, 2006, p. 111-125.

SILVA, T. T. Identidade e diferença: a perspectiva dos estudos culturais. Petrópolis, Vozes, 2000.

SOUSA, S. C. T. de.; ROCA, M. del P. Introdução para uma compreensão ampliada de Política Linguística. In: SOUSA, S. C. T. de.; ROCA, M. del P. (org.). Políticas linguísticas: declaradas, praticadas e percebidas. João Pessoa: Editora da UFPB, 2015. p. 7-23.

SPOLSKY, B. Language Policy. In: COHEN, J. et al. Procedings of the 4th International Symposium on Bilingualism. Somerville, MA: Cascadilla Press, 2005, p. 2152-2164. Disponível em: http://www.lingref.com/isb/4/168ISB4.PDF. Acesso em: 28 jul. 2018. 
SPOLSKY, B. Para uma Teoria de Políticas Linguísticas. ReVEL. Tradução de Paloma Petry. Revisão técnica de Pedro M. Garcez. v. 14, n. 26, p. 32-44, 2016. Disponível em: http://revel.inf.br/files/f69d74cdefbd9c6efb801010f2ac8b13.pdf. Acesso em: 30 ago. 2019.

\section{(ㅇ) (1) $\circledast$}

Recebido em 29/04/2020. Aceito em 10/06/2020. 